\title{
The Protective Role of Scoparia Dulcis Linn. in Alzheimer's Disease
}

\author{
Netnapa Chana*, Thitinan Aiebchun, Pattranit Pinwanit and Asadhawut Hiranrat
}

Department of Chemistry, Faculty of Science, Thaksin University, Phatthalung campus, Phatthalung 93210, Thailand

('Corresponding author's e-mail: netnapa@tsu.ac.th)

Received: 30 March 2021, Revised: 6 June 2021, Accepted: 30 June 2021

\begin{abstract}
Alzheimer's disease (AD) is a neurodegenerative disorder that appears simultaneously with age. AD is caused by oxidative stress, which generates the oxidation of biomolecules such as DNA, proteins, and lipids. The present study aimed to evaluate protein and lipid protection against damage caused by the free radical and anticholinesterase properties of Scoparia dulcis, which are relevant to AD therapy. Furthermore, phytochemical profiling of $S$. dulcis extract was also observed. Quantitative phytochemical (phenolic, flavonoid and tannin contents) analysis of methanol, butanol, and ethyl acetate fraction substances in $S$. dulcis was performed by standard spectrophotometric methods. Butanolic extracts showed maximum amounts of phytochemicals, including phenolics, flavonoids, and tannins. The butanolic extract also showed the highest acetylcholinesterase potential inhibition and DPPH radical scavenging, with $\mathrm{IC}_{50}$ values of 93.24 and $22.8 \mu \mathrm{g} / \mathrm{mL}$, respectively, in a dose-dependent manner. Additionally, the butanol fraction exhibited strong $\mathrm{FeSO}_{4}$-induced lipid peroxidation inhibition. The best free-radical-induced protein oxidation inhibitory activity was observed in methanol samples. In conclusion, this study suggests that $S$. dulcis is a potential agent for drug development against AD.
\end{abstract}

Keywords: Scoparia dulcis Linn., Phytochemical profile, Protein damage, Lipid damage, Acetylcholinesterase activity

\section{Introduction}

Alzheimer's disease (AD) is the most common form of dementia and the prevailing neurodegenerative disorder in the world, and it has become an imperative public health concern because there is no real cure. The prevalence rate of AD will double every 20 years until at least 2050 [1]. AD is characterised by the formation of senile plaques composed of amyloid beta protein (A $\beta)$, the formation of neurofibrillary tangles (NFT), oxidative stress, and substantial loss of the cholinergic neuron. It has been reported that loss of the neurotransmitter acetylcholine is responsible for the total dysfunction of cholinergic neurotransmission that is observed in $\mathrm{AD}$, which accounts for cognitive deficits [2]. Acetylcholinesterase is the primary enzyme responsible for the breakdown of acetylcholine within synapses of the cerebral cortex. Consequently, acetylcholinesterase inhibitors can be employed for the treatment of $\mathrm{AD}$. The cholinesterase inhibitors donepezil, rivastigmine, and memantine have been employed for the treatment of severe AD [3]. However, these drugs are known to have disparaging side effects that include disturbing nausea, vomiting, diarrhoea, dizziness, and weight loss [4]. The increasing of reactive oxygen species (ROS) level disrupted calcium homeostasis and altered membrane integrity leading to neuronal death. Oxidative stress in astrocytes promotes $A \beta$ formation in the brain [5]; therefore, the use of natural dietary antioxidants that can interfere or inhibit oxidative stress is a promising approach. ROS are generated within the body by multiple metabolic processes. They play a pivotal role in the immune response and cell signalling. Free radicals that have 1 or more unpaired electrons stabilise themselves by electron pairing with biomolecules such as lipids, proteins, and nucleic acids, causing damage to biomolecules in an organism. The aberrant accumulation of ROS is the primary factor in the pathogenesis of AD in both human brains and animal models, suggesting that ROS may contribute to the pathogenesis of these diseases by inducing oxidative stress [6]. Interestingly, antioxidants have significant potential to reduce the symptoms and incidence of AD. Most natural acetylcholinesterase inhibitor molecules present antioxidant activity, which enables them to be applied as multi-target strategies against $\mathrm{AD}$ onset and progression [7]. However, the availability of natural acetylcholinesterase inhibitors is 
limited. Previous studies have already highlighted the potential of plants as vital sources for cholinesterase inhibitors and antioxidants $[6,8]$.

Scoparia dulcis, also known as sweet broom, is an herbal medicinal plant that is widely used in the indigenous system of medicine. A previous report revealed that $S$. dulcis extract and its active compounds may exert effects in cases of diabetes and may act as an anticancer agent $[9,10]$. Our previous report revealed that the fresh aerial part of $S$. dulcis extract displays antibacterial activity. In addition, the presence of the $S$. dulcis extract protected Sf9 cells against $\mathrm{H}_{2} \mathrm{O}_{2}$-induced cell death [11]. S.dulcis provides anti-oxidative property in noise-induced redox imbalance in rat brain [12]. The extract of $S$. dulcis displays therapeutic potential for the treatment of osteoarthritis due to its anti-inflammatory and anti-nociceptive action [13]. S. dulcis extract could control motor impairment and regulate neurotransmitter levels [14]. However, the therapeutic benefits of $S$. dulcis in AD are unknown. Therefore, the objective of this research was to evaluate the anti-cholinesterase and antioxidant properties and the protection of biomolecules from free radicals of the crude extract of $S$. dulcis in different solvents.

\section{Materials and methods}

\section{Plant material and preparation of the extracts from $S$. dulcis}

S. dulcis samples were collected in August 2017 from Thailand (Songkhla province), and the collected plant was authenticated by a taxonomist and identified by the ITS2 gene, as presented in our previous report [11]. The aerial parts were shade dried for 20 days at room temperature. The plant was powdered and extracted by maceration using 3 different solvents (methanol, butanol, and ethyl acetate) at a sample: solvent ratio of 1:10 for 3 days. The extracted substance was filtered through Whatman No.1 filter and subjected to evaporation.

\section{Phytochemical analysis}

The powdered extracts were evaluated for the qualitative determination of the following major phytoconstituents using standard methods: Saponins, alkaloids, phenolics, flavonoids, tannins, and terpenoids. Quantitative determination of phenolics, flavonoids, and tannins was also carried out.

\section{Determination of total phenolic content}

The total phenolic content in the extracts was determined by employing a modified Folin-Ciocalteu method [15]. The plant extract solution $(30 \mu \mathrm{L}, 1 \mathrm{mg} / \mathrm{mL})$ was mixed with diluted Folin-Ciocalteu reagent $(110 \mu \mathrm{L}, 1: 10, \mathrm{v} / \mathrm{v})$, and then the samples were shaken vigorously. After $3 \mathrm{~min}, \mathrm{Na}_{2} \mathrm{CO}_{3}$ solution $(110 \mu \mathrm{L}, 7.5 \%)$ was added, and the sample absorbance was measured at $765 \mathrm{~nm}$ after 15 min of incubation at $45^{\circ} \mathrm{C}$. Gallic acid was processed in a similar method to provide a standard curve. The total phenolic content was expressed as milligrams of gallic acid equivalents on a weight basis (mg GAE/g extract).

\section{Determination of total flavonoid content}

The total flavonoid content of the plant extracts was determined using the $\mathrm{AlCl}_{3}$ method [15]. In brief, $20 \mu \mathrm{L}$ of the sample solution $(1 \mathrm{mg} / \mathrm{mL})$ was mixed with aluminium trichloride $(50 \mu \mathrm{L}, 2 \%)$ in methanol. Similarly, a blank was prepared by adding the sample solution to methanol without $\mathrm{AlCl}_{3}$. After incubation at room temperature for $10 \mathrm{~min}$, the sample and blank absorbance were read at $415 \mathrm{~nm}$. The absorbance of the blank was subtracted from that of the sample. Quercetin was used as a reference compound, and the total flavonoid content was expressed as milligrams of quercetin equivalents/g extract.

\section{Determination of tannin content}

The tannins were determined by the method described by Rebaya et al. (2014) using catechin as a reference compound [16]. About $400 \mu \mathrm{L}$ of the extract was added to $3 \mathrm{~mL}$ of vanillin ( $4 \%$ in methanol) and $1.5 \mathrm{~mL}$ of concentrated hydrochloric acid. The mixture was shaken well and kept at room temperature for $15 \mathrm{~min}$. The absorbance was read at $500 \mathrm{~nm}$. The condensed tannin was expressed as $\mathrm{mg}$ of catechin equivalents/g extract.

\section{DPPH radical scavenging assay}

The free radical scavenging activity of the extracts was determined using the stable DPPH (1, 1diphenyl-2-picrylhydrazyl) radical as previously described by Rebaya et al. (2014) with slight modifications [16]. Serial dilutions of the samples were prepared in methanol and were added to $150 \mu \mathrm{L}$ of $0.2 \mathrm{mM}$ DPPH in methanolic solution. The reaction mixture was then incubated in the dark at room 
temperature for $30 \mathrm{~min}$. The sample absorbance was measured at $517 \mathrm{~nm}$. Ascorbic acid (as a standard solution) was assayed under similar conditions. The inhibition percentage of the free radical DPPH (I \%) was calculated using the following formula;

$(\mathrm{I} \%)=[($ Acontrol - Asample $) /$ Acontrol $] \times 100$

where Acontrol is the absorbance of the control and Asample is the absorbance of the sample. The tests were carried out in triplicate, and the results were expressed as the $\mathrm{IC}_{50}$ value, i.e., the concentration of the sample necessary to reduce the DPPH radical by $50 \%$.

\section{Lipid peroxidation inhibition}

Determination of the inhibition of lipid peroxidation was evaluated using work by Upadhyay et al. (2014), with minor modifications [17]. The egg yolk was individually homogenised with cold phosphatebuffered saline ( $\mathrm{pH}$ 7.4). S. dulcis extracts were added to the $3 \mathrm{~mL}$ of homogenate, and lipid peroxidation was initiated by adding $100 \mu \mathrm{L}$ of ferrous sulfate $(15 \mathrm{mM})$. The mixture was shaken and incubated at 37 ${ }^{\circ} \mathrm{C}$ for $30 \mathrm{~min}$. Ten percent homogenate was prepared and filtered on ice to obtain a clear homogenate. Ten percent TCA was added to the $100 \mu \mathrm{L}$ aliquot. After $10 \mathrm{~min}$, the mixture was centrifuged, and the supernatant was mixed with $1.5 \mathrm{~mL}$ of $0.67 \%$ TBA in $50 \%$ acetic acid. The mixture was heated at $95{ }^{\circ} \mathrm{C}$ for $30 \mathrm{~min}$. Then, the mixture was centrifuged at 2,200 $\times \mathrm{g}$ for $20 \mathrm{~min}$. The intensity of the pink coloured complex was measured at $535 \mathrm{~nm}$ by a spectrophotometer. The degree of lipid peroxidation was assayed by estimating the TBA reactive substance (TBARS) content, and the results were expressed as the percent inhibition.

\section{Protein oxidation inhibition}

The protective effect of the $S$. dulcis extract was tested against Fenton's system-generated protein oxidation according to the method by Mohan et al. (2014), with slight modification [18]. Oxidation of BSA (5 mg) in phosphate buffer was initiated by $1 \mathrm{mM} \mathrm{FeCl}_{3}, 2 \mathrm{mM}$ ascorbic acid, and $20 \mathrm{mM} \mathrm{H}_{2} \mathrm{O}_{2}$. The $S$. dulcis extract was added to the mixture at concentrations of $0.5,1$ and $1.5 \mathrm{mg} / \mathrm{mL}$. After incubation for $2 \mathrm{~h}$ at $37{ }^{\circ} \mathrm{C}, 0.02 \%$ BHT was added to prevent the formation of further peroxyl radicals. The samples were then electrophoresed using $12 \%$ SDS-PAGE, and the gel was stained with $0.25 \%$ Coomassie brilliant blue R-250. Images were analysed by Quantity One software from Bio-Rad.

\section{Assay for acetylcholinesterase inhibitory activity}

Acetylcholinesterase (AChE) activity was measured according to the Ellman method within a 96well microtitre plate [19]. Fifty microlitres of the plant extracts at different concentrations were mixed with $20 \mu \mathrm{L}$ of AChE (Electric eel acetylcholinesterase, Type-VI-S, EC 3.1.1.7, Sigma) in Tris-HCl buffer ( $\mathrm{pH} 8.0$ ) containing $0.1 \% \mathrm{BSA}$ and $70 \mu \mathrm{L}$ of 5,5-dithio-bis (2-nitrobenzoic) acid (DTNB) (Sigma, St. Louis, MO, USA) (3 mM) in a 96-well microtitre plate. The plate was incubated for $15 \mathrm{~min}$. The reaction was then initiated by the addition of $20 \mu \mathrm{L}$ of acetylthiocholine iodide (ATCI, Sigma) (15 mM). Similarly, a blank was prepared by adding the sample solution to all reaction reagents without the enzyme (AChE) solution. A control reaction was carried out using phosphate buffer instead of the test compounds. The sample, control reaction, and blank absorbances were read at $405 \mathrm{~nm}$ after 20 min of incubation at room temperature. The absorbance of the blank was subtracted from that of the sample, and the acetylcholinesterase inhibitory activity was expressed as the percentage of enzyme inhibition using the following formula;

$(\mathrm{I} \%)=[($ Acontrol - Asample $) /$ Acontrol $] \times 100$

The $\mathrm{IC}_{50}$ of the extract and galantamine was calculated from the graph.

\section{Statistical analysis}

All experiments were carried out in triplicates and the data are expressed as mean \pm standard deviation $(\mathrm{n}=3)$. A 1-way ANOVA with Duncan's multiple range test was used to compare the differences between group data sets. Statistical significance was defined as $p<0.05$. 


\section{Results and discussion}

Phytochemical analysis

$\mathrm{AD}$ is a neurodegenerative disease resulting in problems related to memory, cognition, and behaviour. The incidence of $\mathrm{AD}$ is increasing. There is increasing interest in finding natural bioactive molecules in order to avoid side effects associated with synthetic drugs. Natural compounds possessing antioxidant properties have the capacity to modulate the progression and symptoms of AD. S. dulcis are known for their therapeutic benefits and antioxidant properties [11] and have widespread use as a traditional medicine. The methanolic, butanolic, and ethyl acetate extracts of $S$. dulcis were prepared using maceration extraction and were subjected to qualitative and quantitative estimation of phytochemical constituents. The phytochemical investigation of $S$. dulcis extracts is summarised in Table 1. It revealed the presence of various phytoconstituents, such as phenolics, flavonoids, terpenoids, and tannins.

Table 1 Phytochemical profiling in the different extract of S. dulcis.

\begin{tabular}{ccc}
\hline Type of plant extracts & Phytochemicals & Results \\
& Phenolic compounds & + \\
& Flavonoids & + \\
Ethyl acetate & Alkaloids & - \\
& Terpenoids & + \\
& Tannins & - \\
\hline \multirow{2}{*}{ Butanol } & Saponins & + \\
& Phenolic compounds & + \\
& Flavonoids & + \\
& Alkaloids & + \\
& Terpenoids & - \\
\hline & Tannins & + \\
& Saponins & + \\
& Phenolic compounds & + \\
& Flavonoids & + \\
& Alkaloids & + \\
& Terpenoids & - \\
\hline
\end{tabular}

Note: + is Positive (present); - is Negative (absent).

Quantitative estimation revealed that the extracts of $S$. dulcis retained phenolic, flavonoid, and tannin contents, and their quantities showed solvent-type-dependent variations (Figure 1). Overall, butanolic extracts displayed the highest levels of phytochemicals, including phenolics, flavonoids, and tannins. The results showed that the butanolic extracts possessed large amounts of tannins (80.44 mg tannic acid equivalent/g extract), total phenolics, (44.40 mg gallic acid equivalent/g extract), and flavonoids (35.71 mg quercetin equivalent/g extract). The ethyl acetate fraction was found to have large amounts of total phenolics $(38.96 \mathrm{mg} / \mathrm{g}$ extract) and tannins $(25.10 \mathrm{mg}$ tannic acid equivalent/g extract); however, the ethyl acetate fraction had the lowest level of flavonoids $(6.07 \mathrm{mg} / \mathrm{g}$ extract). The methanolic fraction had total phenolics (31.75 mg gallic acid equivalent/g extract), flavonoids (21.48 $\mathrm{mg}$ quercetin equivalent/g extract), and tannins (44.53 mg tannic acid equivalent/g extract). Khan et al. (2018) revealed that flavonoids, a heterogeneous group of polyphenols, are currently considered a prominent source of anti-AD compounds [20]. Flavonoids (catechins) within tea offer benefits for reducing the risk of Alzheimer's disease by preventing the formation of amyloid- $\beta$ plaques and enhance cognitive functions [21]. In addition, many phenolic phytochemicals have demonstrated efficacy against many of the other factors contributing to $\mathrm{AD}$ [22]. Resveratrol is one of the phenolic compounds in fruits, showed antioxidant properties and protective roles in neurological disorders [23]. In this study, butanolic extracts displayed the highest levels of phytochemicals. 


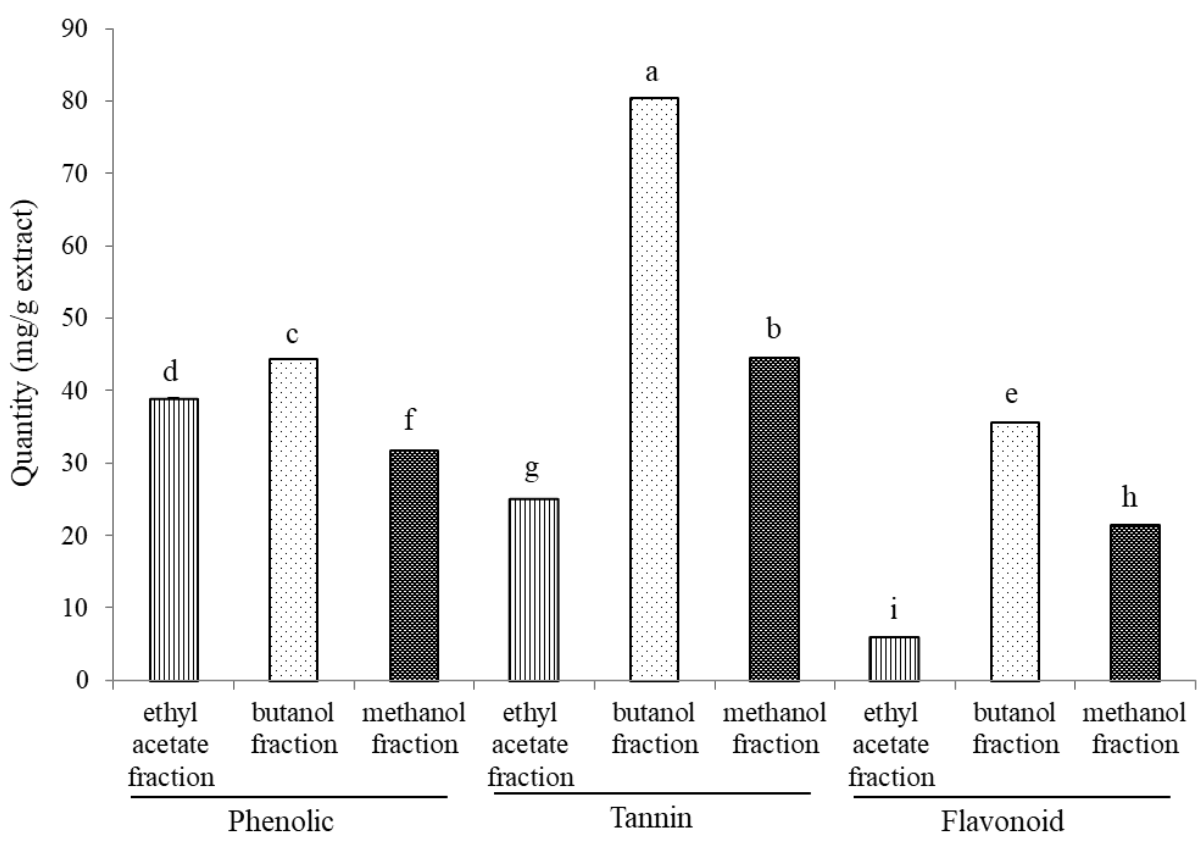

Figure 1 Total phenolic, tannin, and flavonoid content of $S$. dulcis ethyl acetate, butanol, and methanol extracts. The bars with different letters indicate a significant difference $(p<0.5)$ among groups.

\section{Acetylcholinesterase inhibitory activity of $S$. dulcis}

$\mathrm{AD}$ is a progressive neurodegenerative disorder accompanied by oxidative stress, and the levels of acetylcholine in the brain are depressed. Acetylcholinesterase is implicated in the development of AD, and acetylcholinesterase inhibitors were used to maintain cholinergic transmission in the AD brain [24]. The anti-cholinesterase potential of Emblica officinalis, Nardostachys jatamansi, Nelumbo nucifera, Punica granatum, and Raulfia Serpentina extracts have been reported before since they were used in Ayurvedic folk medicine for cognitive disorders [25]. In this study, the S. dulcis extracts exhibited concentration-dependent AChE inhibitory activity for methanol, butanol, and ethyl acetate extracts. The butanol extract was the most potent $\mathrm{AChE}$ inhibitor, with an $\mathrm{IC}_{50}$ value of $93.24 \mu \mathrm{g} / \mathrm{mL}$ (Table 2). Galantamine was used as a positive control $\left(\mathrm{IC}_{50}\right.$ of $\left.13 \mu \mathrm{g} / \mathrm{mL}\right)$. The descending order of AChE inhibitory activity for the extracts was butanolic $>$ methanolic $>$ ethyl acetate extract. These butanol fractions show particular promise for further development and purification for AD treatment.

\section{The $S$. dulcis extract displayed DPPH scavenging activity}

To combat the multifaceted nature of AD, additional off-target actions, such as radical scavenging and biomolecule protection activities, would be of benefit. Free radical scavenging potential was investigated using the DPPH radical scavenging assay along with the protection against oxidative protein and lipid damage. The $\mathrm{IC}_{50}$ of the butanol fraction was $22.81 \mu \mathrm{g} / \mathrm{mL}$ (Table 2), displayed the most potent $\mathrm{DPPH}$ radical scavenging activity. The $\mathrm{IC}_{50}$ values in ethyl acetate and methanol fractions were 171.8 and $491.2 \mu \mathrm{g} / \mathrm{mL}$, respectively. Coulibaly et al. (2011) studied the antioxidant properties of hexane, chloroform, and methanol extracts of $S$. dulcis by the DPPH and FRAP assays. They found that the chloroform extract exhibited the highest activity [26]. Latha et al. (2004) studied the antioxidant properties of the aqueous, ethanolic, and chloroform extracts of $S$. dulcis. The results showed that the water extract possessed the highest activity [27]. Our previous study revealed that methanolic and butanolic extract exhibited an efficiency of supercoiled plasmid DNA damage inhibition better than ethyl acetate, chloroform, and hexane fraction [28]. In this study, the butanolic S. dulcis extracts demonstrated potent AChE inhibitory and DPPH radical scavenging activity and contained a relatively high content of phytochemicals. Liu et al. (2004) revealed the bioactive compounds in S. dulcis, such as flavonoids scutellarein, apigenin, and luteolin showed in vitro $\alpha$-glucosidase inhibitory activities [29]. The present study suggests that butanolic $S$. dulcis could act as a bioresource for use in AD therapies. 
Table 2 Acetylcholinesterase (AChE) inhibitory and DPPH radical scavenging activity of $S$. dulcis ethyl acetate, butanol, and methanol fraction. Galantamine and ascorbic acid are used as standards.

\begin{tabular}{ccc}
\hline Samples & AchE inhibitory & DPPH radical scavenging \\
$\mathbf{I C}_{\mathbf{5 0}}(\boldsymbol{\mu \mathbf { g } / \mathbf { m L } )}$ \\
\hline Ethyl acetate extract & $635.46 \pm 7.55^{\mathrm{d}}$ & $171.8 \pm 0.003^{\mathrm{c}}$ \\
Butanol extract & $93.24 \pm 2.58^{\mathrm{b}}$ & $22.81 \pm 0.04^{\mathrm{b}}$ \\
Methanol extract & $355.36 \pm 4.77^{\mathrm{c}}$ & $491.2 \pm 15.93^{\mathrm{d}}$ \\
Ascorbic acid & nd & $3.70 \pm 0.01^{\mathrm{a}}$ \\
Galantamine & $13.07 \pm 0.11^{\mathrm{a}}$ & nd \\
\hline
\end{tabular}

Values (means of 3 replicates) followed by different letters are significantly different at $p<0.05$. nd $=$ not determined.

\section{Protection of protein oxidation and lipid peroxidation damage}

The relationship between oxidative damage and $\mathrm{AD}$ has received increased recognition in the last decade. Oxidative damage can occur in neuronal cells. The resultant excessive production of reactive oxygen damages the cellular antioxidant defence mechanisms and triggers the occurrence of AD [30]. Oxidation of biomolecules, such as carbohydrates, proteins, lipids, and nucleic acids, results in the generation of free radicals in an organism. Free radicals are implicated with cellular disorders and are causative factors of various degenerative diseases and the aging process. Antioxidants scavenge these free radicals, thereby protecting tissue damage. Our report revealed that the S.dulcis extract has antimicrobial properties and protects cells from hydrogen peroxide [11]. The present study was designed to examine the protection against oxidative protein and lipid damage of $S$. dulcis. Extracts were evaluated for oxidative damage protective activity, and the results are illustrated in Figures 2(A) and 2(B). Hydroxyl radicals generated by Fenton's reaction are known to cause BSA protein degradation. In the present investigation, a small band of protein was observed (Figures 2(A) and (B)). All extracts showed observable protection of protein intactness, which can be seen in terms of restoration of band intensity in the gel. Methanolic extracts significantly protected the protein from free-radical-induced oxidation (Figure 2(C)), with the relative intensity equal $59.35 \%$. Lovell et al. observed protein, lipid, and DNA oxidation in brain tissues of AD patients [31]. These results hold significance and may have a positive role in inhibiting stress- or toxicity-induced protein oxidation.

Oxidants can damage virtually all biological molecules, such as DNA, RNA, cholesterol, lipids, carbohydrates, proteins, and antioxidants [32-34]. In the brain of those with $\mathrm{AD}$, numerous studies have demonstrated that lipid peroxidation is increased, with an associated increase in protein oxidation [35,36]. Therefore, inhibition of lipid peroxidation is considered the most important index of antioxidant potential. Table 3 illustrates that $S$. dulcis has tremendous potential in terms of lipid peroxidation inhibition. All the extracts showed concentration-dependent inhibition. The butanolic fraction showed the highest percentage of inhibition, whereas the ethyl acetate extracts showed the lowest inhibition among all extracts. The butanolic extracts offered a good degree of protection against the biological end-point of oxidative damage and showed $78.93 \%$ lipid peroxidation inhibition at the concentration of $1 \mathrm{mg} / \mathrm{mL}$. The test sample could prevent the initiation of lipid peroxidation by chelating or reducing the iron ion or by scavenging the free radical produced within the propagation phase of lipid peroxidation. Lizcano et al. (2012) revealed that polyphenols from medicinal plants inhibit lipid oxidation by acting as chain-breaking peroxyl-radical scavengers [37]. That observation can be supported by the previous studies about the protective role of $S$. dulcis against neuroinflammation and erythrocyte haemolysis [26]. As a result, there is intense scientific interest in discovering more potent AChE inhibitors and antioxidant effects that protect protein and lipid biomolecules. The natural antioxidants that are present in S. dulcis may inhibit or prevent the deleterious consequences of oxidative stress. The results from our study suggest that butanolic S. dulcis could be used for the treatment of AD. 
Table 3 Inhibition of iron-induced lipid peroxidation by $S$. dulcis extract. The egg yolk was incubated with $\mathrm{FeSO}_{4}$ in the presence of increasing quantities of $S$. dulcis.

\begin{tabular}{ccc}
\hline Type of plant extracts & Concentration $\mathbf{( m g / m L )}$ & \% Lipid peroxidation inhibition \\
\hline Butanol extract & 0.5 & $61.11 \pm 1.01^{\mathrm{c}}$ \\
Butanol extract & 1 & $78.93 \pm 9.60^{\mathrm{a}}$ \\
Methanol extract & 0.5 & $65.63 \pm 0.51^{\mathrm{bc}}$ \\
Methanol extract & 1 & $75.97 \pm 14.17^{\mathrm{ab}}$ \\
Ethyl acetate extract & 0.5 & $53.04 \pm 3.21^{\mathrm{c}}$ \\
Ethyl acetate extract & 1 & $58.21 \pm 0.38^{\mathrm{c}}$ \\
\hline
\end{tabular}

Values (means of 3 replicates) followed by different letters are significantly different at $p<0.05$.

(A)

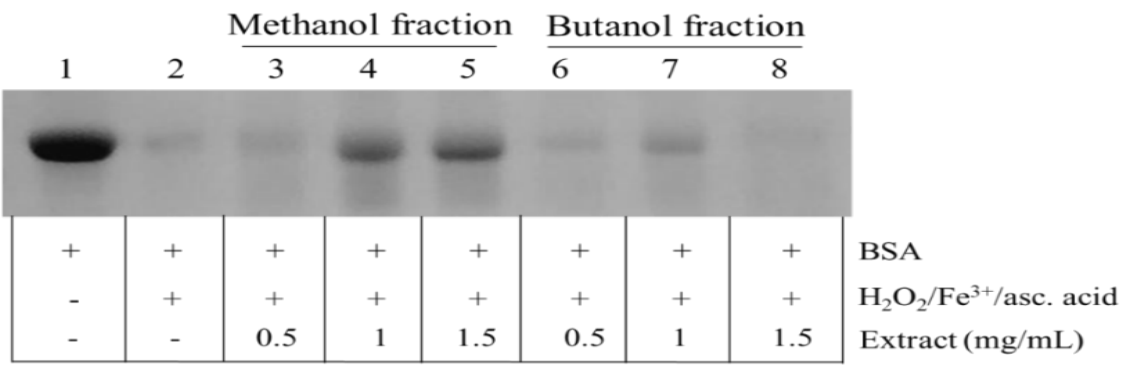

(B)

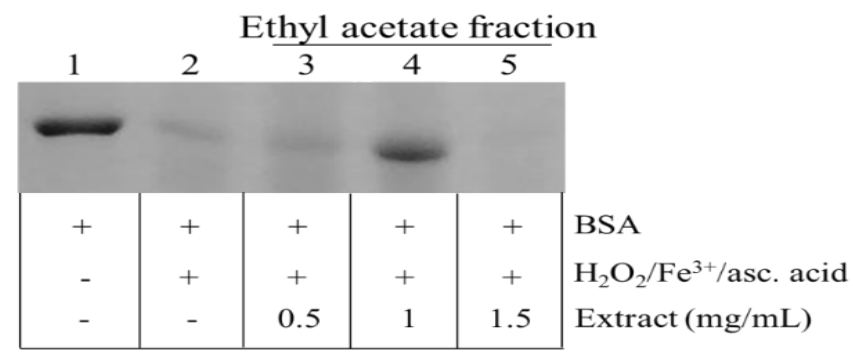

(C)

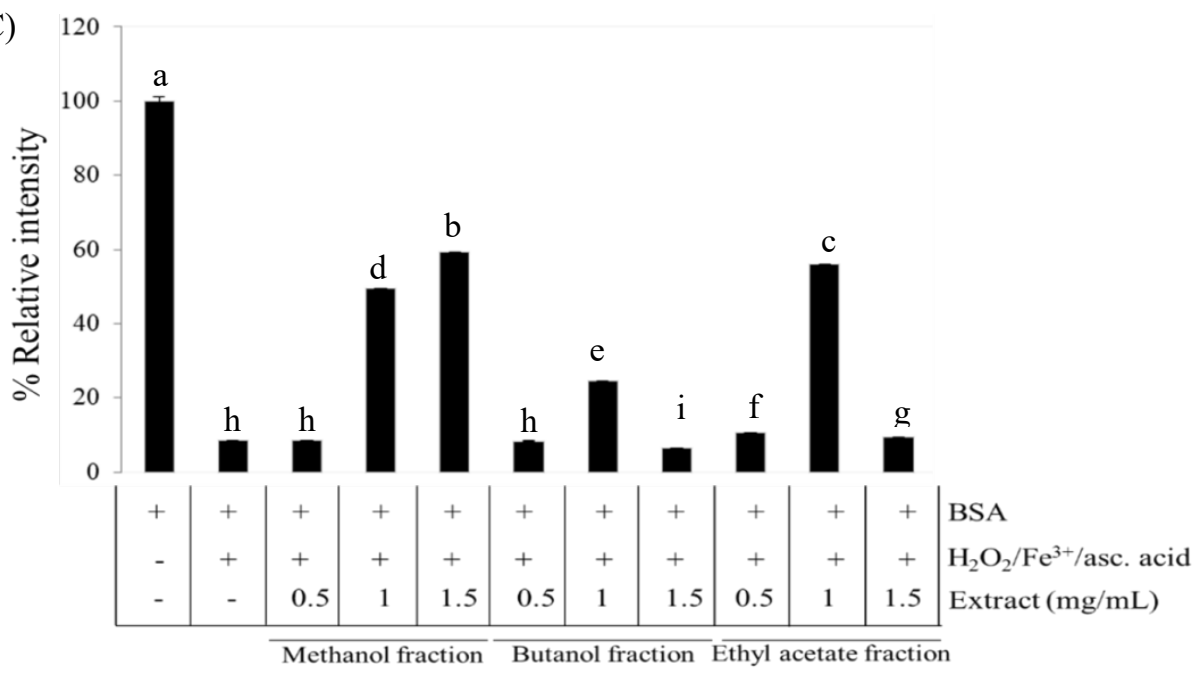

Figure 2 Protection protein oxidation damage of the extract from S.dulcis. (A) and (B); Data represent SDS-PAGE analysis of methanol, butanol, and ethyl acetate fractions. (C); Image analysis with Quantity One software from Bio-Rad, and the results expressed as a percentage (\%) relative intensity of all the extract.

Different letters indicate a significant difference among groups according to Duncan's multiple range test $(p<0.05)$. 


\section{Conclusions}

S. dulcis extracts possess antioxidant capacity and anti-AChE activity. The substance reduced oxidative stress by reactive molecule scavenging, which decreased protein oxidation and lipid peroxidation. S. dulcis could be used as a therapeutic agent for those suffering from AD or other diseases characterised by a cholinergic deficit.

\section{Acknowledgements}

This research was supported by research grants from Thaksin University. Our thanks go to department of Chemistry, the Faculty of Science, Thaksin University for allowing us to use laboratory facilities.

\section{References}

[1] P Scheltens, K Blennow, MMB Breteler, BD Strooper, GB Frisoni, S Salloway and WMVD Flier. Alzheimer's disease. Lancet 2016; 388, 505-17.

[2] A Sanabria-Castro, I Alvarado-Echeverría and C Monge-Bonilla. Molecular pathogenesis of Alzheimer's disease: An Update. Ann Neurosci. 2017; 24, 46-54.

[3] WJ Deardorff and GT Grossberg. Pharmacotherapeutic strategies in the treatment of severe Alzheimer's disease. Expet. Opin. Pharmacother. 2016; 17, 1789-800.

[4] CC Tan, JT Yu, HF Wang, MS Tan, XF Meng, C Wang, T Jiang, XC Zhu and L Tan. Efficacy and safety of donepezil, galantamine, rivastigmine, and memantine for the treatment of Alzheimer's disease: A systematic review and meta-analysis. J. Alzheimers Dis. 2014; 41, 615-31.

[5] S Elangovan and RMD Holsinger. Cyclical amyloid beta-astrocyte activity induces oxidative stress in Alzheimer's disease. Biochimie 2020; 171-172, 38-42.

[6] ASM Ali Reza, MS Hossain, S Akhter, MR Rahman, MS Nasrin, MJ Uddin, G Sadik and AHM Khurshid Alam. In vitro antioxidant and cholinesterase inhibitory activities of Elatostema papillosum leaves and correlation with their phytochemical profiles: A study relevant to the treatment of Alzheimer's disease. BMC Compl. Alternative Med. 2018; 18, 123.

[7] AK Sahoo, J Dandapat, UC Dash and S Kanhar. Features and outcomes of drugs for combination therapy as multi-targets strategy to combat Alzheimer's disease. J. Ethnopharmacol. 2018; 215, 42-73.

[8] M Penumala, RB Zinka, JB Shaik and DA Gangaiah. In vitro screening of three indian medicinal plants for their phytochemicals, anticholinesterase, antiglucosidase, antioxidant, and neuroprotective effects. BioMed Res. Int. 2017; 2017, 5140506.

[9] JE Beh, J Latip, MP Abdullah, A Ismail and M Hamid. Scoparia dulcis (SDF7) endowed with glucose uptake properties on L6 myotubes compared insulin. J. Ethnopharmacol. 2010; 129, 23-33.

[10] W Wu, T Chen, R Lu, S Chen and C Chang. Benzoxazinoids from Scoparia dulcis (sweet broomweed) with antiproliferative activity against the DU-145 human prostate cancer cell line. Phytochemistry 2012; 83, 110-5.

[11] N Chana, P Supaphon and A Phongdara. Evaluation of antibacterial, antioxidant activity and calmodulin gene expression of Scoparia dulcis Linn. Songklanakarin J. Sci. Tech. 2019; 41, 246-53.

[12] W Wankhar, S Srinivasan, R Rajan and R Sheeladevi. Antioxidant mediated response of Scoparia dulcis in noise-induced redox imbalance and immunohistochemical changes in rat brain. J. Biomed. Res. 2017; 31, 143-53.

[13] MVV Lima, ADO Freire, ELF Sousa, AAM Vale, AJO Lopes, CC Vasconcelos, MVV LimaAragão, HO Serra, RNMG Liberio, APSDAD Santos, GEB Silva, CQD Rocha, FCVM Lima, MDSDS Cartágenes and JBS Garcia. Therapeutic use of Scoparia dulcis reduces the progression of experimental osteoarthritis. Molecules 2019; 24, 3474.

[14] W Wankhar, S Srinivasan, L Sundareswaran, D Wankhar, R Rajan and R Sheeladevi. Role of Scoparia dulcis linn on noise-induced nitric oxide synthase (NOS) expression and neurotransmitter assessment on motor function in Wistar albino rats. Biomed. Pharmacother. 2017; 86, 475-81.

[15] D Kim, SW Jeong and CY Lee. Antioxidant capacity of phenolic phytochemicals from various cultivars of plums. Food Chem. 2003; 81, 321- 6.

[16] A Rebaya, SL Belghith, B Baghdikian, VM Leddet, F Mabrouki, E Olivier, JK Cherif and MT Ayadi. Total phenolic, total flavonoid, tannin content, and antioxidant capacity of Halimium halimifolium (Cistaceae). J. Appl. Pharm. Sci. 2015; 5, $52-7$. 
[17] R Upadhyay, JK Chaurasia, KN Tiwari and K Singh. Antioxidant property of aerial parts and root of Phyllanthus fraternus Webster, an important medicinal plant. Sci. World J. 2014; 24, 692392.

[18] S Mohan, K Thiagarajan and R Chandrasekaran. In vitro protection of biological macromolecules against oxidative stress and in vivo toxicity evaluation of Acacia nilotica (L.) and ethyl gallate in rats. BMC Compl. Alternative Med. 2014; 14, 257.

[19] GL Ellman, KD Courtney, V Andreas and RM Featherstone. A new and rapid colorimetric determination of acetylcholinesterase activity. Biochem. Pharmacol. 1961; 7, 88-90.

[20] H Khan, Marya, S Amin, MA Kamal and S Patel. Flavonoids as acetylcholinesterase inhibitors: current therapeutic standing and future prospects. Biomed. Pharmacother. 2018; 101, 860-70.

[21] WMADB Fernando, G Somaratne, KG Goozee, S Williams, H Singh and RN Martins. Diabetes and Alzheimer's disease: Can tea phytochemicals play a role in prevention? J. Alzheimers Dis. 2017; 59, 481-501.

[22] E Wightman. Potential benefits of phytochemicals against Alzheimer's disease. Proc.Nutr. Soc. 2017; 76, 106-12.

[23] G D’Onofrio, D Sancarlo, Q Ruan, Z Yu, F Panza, A Daniele, A Greco and D Seripa. Phytochemicals in the treatment of Alzheimer's disease: A systematic review. Curr. Drug Targets. 2017; 18, 1487-98.

[24] MB Colović, DZ Krstić, TD Lazarević-Pašti, AM Bondžić and VM Vasić. Acetylcholinesterase inhibitors: Pharmacology and toxicology. Curr. Neuropharmacol. 2013; 11, 315-35.

[25] M Mathew and S Subramanian. In vitro screening for anti-cholinesterase and antioxidant activity of methanolic extracts of ayurvedic medicinal plants used for cognitive disorders. PloS one 2014; 9 , e86804.

[26] AY Coulibaly, M Kiendrebeogo, PG Kehoe, PAED Sombié, CE Lamien, JF Millogo and OG Nacoulma. Antioxidant and anti-Inflammatory effects of Scoparia dulcis L. J. Med. Food. 2011; 14, 1576-82.

[27] M Latha, L Pari, S Sitasawad and R Bhonde. Scoparia dulcis, a traditional antidiabetic plant, protects against streptozotocin induced oxidative stress and apoptosis in vitro and in vivo.J. Biochem. Mol. Toxicol. 2004; 18, 261-72.

[28] N Chana and J Chaikaew. DNA damage protection activities of different solvents from Scoparia dulcis leaf and stem extracts. Khonkaen Agr. J. 2018; 46, 397-408.

[29] Q Liu, Q Yang, H Hu, L Yang, Y Yang, G Chou and Z Wang. Bioactive diterpenoids and flavonoids from the aerial parts of Scoparia dulcis. J. Nat. Prod. 2014; 77, 1594-600.

[30] J Wojsiat, KM Zoltowska, K Laskowska-Kaszub and U Wojda. Oxidant/antioxidant imbalance in Alzheimer's disease: Therapeutic and diagnostic prospects. Oxid. Med. Cell. Longev. 2018; 2018, 6435861 .

[31] MA Lovell and WR Markesbery. Oxidative DNA damage in mild cognitive impairment and latestage Alzheimer's disease. Nucleic Acids Res. 2007; 35, 7497-504.

[32] Q Kong and CG Lin. Oxidative damage to RNA: Mechanisms, consequences, and diseases. Cell. Mol. Life Sci. 2010; 67, 1817-29.

[33] V Cecarini, J Gee, E Fioretti, M Amici, M Angeletti, AM Eleuteri and JN Keller. Protein oxidation and cellular homeostasis: Emphasis on metabolism. Biochim. Biophys. Acta. 2007; 1773, 93-104.

[34] LJ Su, JH Zhang, H Gomez, R Murugan, X Hong, D Xu, F Jiang and ZY Peng. Reactive oxygen species-induced lipid peroxidation in apoptosis, autophagy, and ferroptosis. Oxidative Med. Cell. Longevity. 2019; 2019, 5080843.

[35] Y Kao, P Ho, Y Tu, I Jou and K Tsai. Lipids and Alzheimer's Disease. Int. J. Mol. Sci. 2020; 21, 1505.

[36] DA Butterfield and D Boyd-Kimball. Oxidative stress, amyloid- $\beta$ Peptide, and altered key molecular pathways in the pathogenesis and progression of Alzheimer's disease. J. Alzheimers Dis. 2018; 62, 1345-67.

[37] LJ Lizcano, M Viloria-Bernal, F Vicente, LA Berrueta, B Gallo, M Martínez-Cañamero, MB RuizLarrea and JI Ruiz-Sanz. Lipid oxidation inhibitory effects and phenolic composition of aqueous extracts from medicinal plants of Colombian Amazonia. Int. J. Mol. Sci. 2012; 13, 5454-67. 